\title{
HUBUNGAN MINAT MEMBACA DENGAN KEMAMPUAN BERBAHASA SISWA KELAS V SDN 1 LENEK LAUK TAHUN 2020
}

\author{
Rizqi Fitriyana Surya ${ }^{1)}$, Siti Rohana Hariana Intiana ${ }^{2)}$, Ida Ermiana ${ }^{3)}$ \\ 1) Program Studi PGSD, FKIP - Universitas Mataram \\ 2) Program Studi PGSD, FKIP - Universitas Mataram \\ 3) Program Studi PGSD, FKIP - Universitas Mataram \\ *Corresponding Author: ida_ermiana@unram.ac.id
}

\begin{abstract}
ARTICLE INFO
ABSTRACT

Article history

Received : 1 Agustus 2020

Revised : 15 Agustus 2020

Accepted : 27 Agustus 2020

Keywords:

Reading interest, language ability

How to cite:

Surya, Rizqi Fitriyana, et al. 2020. Hubungan Minat

Membaca dengan Kemampuan

Berbahasa Siswa Kelas V SDN

1 Lenek Lauk Tahun 2020.

Jurnal Pendas, Vol

Penelitian ini bertujuan untuk mengetahui hubungan minat membaca dengan kemampuan berbahasa siswa kelas V SDN 1 Lenek Lauk. Penelitian ini menggunakan pendekatan kuantitatif dengan jenis penelitian survey. Populasi dalam penelitian ini adalah siswa kelas V SDN 1 Lenek Lauk yang berjumlah 28 orang. Teknik pengambilan sampel yang digunakan adalah sampling total, dengan demikian berarti seluruh populasi menjadi sampel. Instrumen penelitian yang digunakan adalah angket minat membaca dengan skala gautmen dan dokumentasi. Teknik analisis data menggunakan uji normalitas dan uji linieritas serta uji hipotesis menggunakan korelasi product moment. Hasil analisi data menunjukan minat membaca siswa berada pada kategori sedang dengan presentase $78,57 \%$ dan kemampuan berbahasa siswa berada pada kategori sedang dengan presentase 64,29\%. Hasil uji hipotesis menunjukan indeks korelasi nilai $r_{\text {hitung }}$ sebesar 0,485 sedangkan nilai $r_{\text {tabel }} 0,375$ pada taraf signifikansi $5 \%$ $(0,485 \geq 0,375)$ dengan koefisien determinasi $23,5225 \%$. Oleh karena itu, dapat disimpulkan terdapat hubungan signifikan antara minat membaca dengan kemampuan berbahasa siswa kelas V SDN 1 Lenek Lauk dengan kontribusi sebesar 23,5\%.
\end{abstract}

Kata Kunci: Minat Membaca, Kemampuan Berbahasa

This research aims to determine the relationship between reading interest and language ability of fifth grade students of SDN 1 Lenek Lauk. This research uses a quantitative approach with survey research type. The population in this reasearch were fifth grade totalling 28 students of SDN 1 Lenek Lauk. The sampling technique used was sampling total, which means that the entire population was sampled. The research instrument used was a reading interest questionnaire with a gautmen scale and documentation. Data analysis techniques used normality test and linearity test and hypothesis testing using product moment correlation. The results of data analysis showed that students 'reading interest was in the medium category with a percentage of $78.57 \%$ and the students' language ability were in the medium category with a percentage of $64.29 \%$. The results of the hypothesis test show that the correlation index value of $r_{\text {count }} i$ s 0.485 while the value of $r_{\text {table }}$ is 0.375 at a significance level of $5 \%$ $(0.485 \geq 0.375)$ with a determination coefficient of $23.5225 \%$. Therefore, it can be concluded that there is a significant relationship between reading interest and language ability of grade V SDN 1 Lenek Lauk students with a contribution of $23.5 \%$. 


\section{A. PENDAHULUAN}

Bahasa sangat penting peranannya dalam kehidupan manusia. Sebagai makhluk sosial, manusia dituntut untuk dapat berkomunikasi dengan baik dengan sesamanya, dan bahasa merupakan aspek utama berkomunikasi. Mengembangkan kemampuan berbahasa sangat diperlukan agar seseorang dapat berkomunikasi semakin baik. Kemampuan berbahasa menurut Rahayu (2012) adalah kesanggupan, kecakapan, kekayaan ucapan pikiran dan perasaan manusia melalui bunyi arbiter, digunakan untuk bekerjasama, berinteraksi, dan mengidentifikasi diri dalam percakapan yang baik.Kemampuan berbahasa juga dapat diartikan sebagai kesanggupan untuk menggunakan lambang-lambang bunyi guna berinteraksi dengan masyarakat. Salah satu cara yang dapat dilakukan untuk meningkatkan kemampuan berbahasa adalah dengan membaca. Dijelaskan oleh Setyowati dalam jurnal penelitiannya (2016) bahwa keterampilan seseorang dalam berbahasa sangat dipengaruhi oleh kualitas pemahaman dan kuantitas kosakata yang dimilikinya, dimana hal tersebut dapat diperoleh seseorang saat membaca. Pembelajaran Bahasa Indonesia merupakan pembelajaran yang kompleks dengan mengutamakan aspek keterampilan berbahasa. Keterampilan berbahasa mencakup empat komponen, yaitu keterampilan menyimak, keterampilan membaca, keterampilan berbicara dan keterampilan menulis (Musaddat, 2017).

Membaca merupakan kegiatan produktif yang sangat penting bagi siswa. Banyak manfaat yang bisa diperoleh dari kegiatan membaca. Tidak hanya untuk meningkatkan wawasan dan pengetahuan, membaca juga dapat meningkatkan kemampuan berbahasa siswa. Namun rupanya banyaknya manfaat membaca tidak sejalan dengan minat membaca masyarakat Indonesia yang rendah.

Rendahnya minat membaca masyarakat Indonesia dibuktikan dengan berbagai survei. Berdasarkan data The Most Littered Nation in The World studi untuk mencari tahu seberapa tinggi minat membaca negara-negara dunia yang dilakukan oleh Connecticut State University (CCSU) pada Maret 2016 lalu. Berdasarkan hasil survei, Indonesia menduduki peringkat ke 60 dari 61 negara dengan kata lain minat baca masyarakat Indonesia hanya 0,01 persen. Sejalan dengan CCSU, hasil penelitian tahun 2015 oleh Program for International Student Assessment (PISA) menunjukan Indonesia berada pada ranking 62 dari 70 negara yang disurvei.

Sinambela dalam Hartono (2016:282) mengatakan, minat membaca adalah sikap positif dan adanya rasa ketertarikan dalam diri seseorang terhadap aktivitas membaca meliputi kesenangan membaca dan tertarik terhadap buku bacaan. Rendahnya minat baca sebuah bangsa akan berimbas pada kualitas sumber daya manusia yang dimilikinya. Melihat hal ini perlu adanya upaya untuk meningkatkan minat baca masyarakat. Salah satu hal yang dapat dilakukan adalah dengan menanamkan kebiasaan membaca sejak dini sehingga menambah pengetahuan dan kemampuan berbahasa serta daya cipta.

Kebiasaan membaca haruslah ditanamkan sedini mungkin, terutama di sekolah dasar, karena membaca sangat penting dalam pembelajaran serta perkembangan kemampuan berbahasa siswa. Pada usia inilah waktu yang tepat untuk menanamkan kebiasaan membaca. Selain untuk kegiatan pembelajaran, membaca juga menjadi bekal bagi siswa dalam kehidupan sehari-hari. 
Berdasarkan uraian di atas minat membaca memiliki hubungan dengan kemampuan berbahasa siswa. Hal ini dikarenakan membaca menjadi kegiatan yang sangat tepat dalam melatih kemampuan berbahasa siswa. Ketiak membaca secara tidak langsung siswa akan lebih mengenal bermacam-macam metode dan teknik berbahasa serta pengetahuanpengetahuan lain yang kemudian dapat digunakan dalam berinteraksi.

\section{B. METODE PENELITIAN}

Penelitian ini merupakan penelitian survei yang dilakukan untuk mengetahui hubungan minat membaca dengan kemampuan berbahasa siswa kelas V SDN 1 Lenek Lauk. Survei digunakan untuk mendapatkan data dari tempat tertentu yang alamiah. Pendekatan yang digunakan dalam penelitian ini adalah pendekatan kuantitatif dikarenakan analisis data yang digunakan bersifat statistik untuk menguji hipotesis yang ditetapkan.

Penelitian ini dilaksanakan pada bulan Oktober 2020 di SDN 1 Lenek Lauk Dasan Nyiur, Lenek Lauk Kecamatan Lenek, Lombok Timur. Populasi dalam penelitian ini adalah seluruh siswa kelas V SDN 1 Lenek Lauk yang berjumlah 28 siswa. Sampel dalam penelitian ini menggunakan sampling total. Hal ini dilakukan karena jumlah populasi relatif kecil.

Instrumen dalam penelitian ini adalah angket dan dokumen. Angket pada penelitian ini berupa angket tertutup dengan skala Gautmen berisi sejumlah item pernyataan tertulis yang disusun dengan mengacu pada indikator minat membaca. Dokumen dimaksudkan untuk mengumpulkan data kemampuan berbahasa yang diperoleh dari penilaian kompetensi dasar mata pelajaran Bahasa Indonesia dalam Kurikulum 2013. Nilai KD Bahasa Indonesia digunakan karena setiap KD memuat keempat aspek kemampuan berbahasa. Adapun teknik analisis data yang digunakan adalah

1. Uji normalitas data menggunakan One-Sample Kolmogorov-Smirnov.

2. Uji linieritas data menggunakan koefisien signifikansi dari deviation from linearity

3. Uji hipotesis menggunakan Product Moment.

\section{HASIL DAN PEMBAHASAN}

Penelitian ini bertujuan untuk mengetahui hubungan minat membaca dengan kemampuan berbahasa siswa kelas V SDN 1 Lenek Lauk. Tahap pertama adalah deskripsi data terhadap variabel minat membaca siswa kelas V SDN 1 Lenek Lauk. Berdasarkan analisis yang dilakukan, diperoleh kesimpulan bahwa siswa kelas V SDN 1 Lenek Lauk yang memiliki minat membaca tinggi berjumlah 2 siswa atau sebesar 7,14\%, kemudian siswa yang memiliki minat membaca sedang berjumlah 22 siswa atau sebesar 78,57\% dan siswa yang memiliki minat membaca rendah berjumlah 4 siswa atau sebesar 14,29\%, sehingga menunjukkan bahwa rata-rata minat membaca siswa berada di tingkat sedang. Hal ini berarti sebanyak 78,57\% siswa cukup memiliki minat dalam membaca.

Selanjutnya dilakukan analisis statistik mengenai variabel kemampuan berbahasa siswa kelas V SDN 1 Lenek Lauk. Berdasarkan analisis yang dilakukan diperoleh kesimpulan bahwa siswa kelas V SDN 1 Lenek Lauk memiliki tingkat kemampuan berbahasa kategori tinggi berjumlah 4 siswa atau sebesar 14,29\%, sedangkan siswa yang memiliki kemampuan berbahasa sedang berjumlah 18 siswa atau sebesar 64,29\%, sementara siswa dengan kemampuan berbahasa kategori rendah sebanyak 6 siswa atau 
sebesar $21,43 \%$, sehingga menunjukkan bahwa rata-rata kemampuan berbahasa siswa kelas V SDN 1 Lenek Lauk berada di tingkat sedang.

Sebelum uji korelasi dilakukan, terlebih dahulu dilaksanakan uji prasyarat analisis data yang terdiri dari uji normalitas dan uji linearitas. Uji normalitas dilakukan untuk mengetahui variabel-variabel yang dianalisis berdistribusi dengan normal atau tidak. Uji normalitas dilakaukan dengan bantuan SPSS 22.

Apabila nilai signifikansi yang diperoleh lebih besar dari 0,05 ( $\mathrm{p}>0,05)$ maka dinyatakan data berdistribusi normal. Sedangkan jika nilai signifikansi yang diperoleh lebih kecil dari 0,05 $(\mathrm{p}<0,05)$ maka data dinyatakan beerdistribusi tidak normal. Berdasarkan tabel hasil uji normalitas minat membaca siswa pada output Test of Normality KolmogorovSmirnov diketahui taraf signifikansi data sebesar 0,200 dengan responden sebanyak 28 siswa. Nilai signifikansi 0,200 > 0,05 artinya data minat membaca siswa kelas V SDN 1 Lenek Lauk yang diperoleh berdistribusi normal.

Tabel 1. Hasil Uji Normalitas Data Minat Membaca Siswa

\begin{tabular}{|c|c|c|}
\hline & & Minat Membaca \\
\hline $\mathrm{N}$ & & 28 \\
\hline Normal Parameters ${ }^{\mathrm{a}, \mathrm{b}}$ & Mean & 25.5000 \\
\hline & Std. Deviation & 7.81499 \\
\hline Most Extreme & Absolute & .119 \\
\hline Differences & Positive & .071 \\
\hline & Negative & -.119 \\
\hline Test Statistic & & .119 \\
\hline Asymp. Sig. (2-tailed) & & $200^{\mathrm{c}, \mathrm{d}}$ \\
\hline
\end{tabular}

Begitupula dengan data kemampuan berbahasa siswa, berdasarkan pada tabel hasil uji normalitas kemampuan berbahasa siswa pada output Test of Normality KolmogorovSmirnov perolehan taraf signifikansi sebesar 0,104 dengan responden sebanyak 28 siswa. Nilai sidnifikansi 0,104 > 0,05 artinya data kemampuan berbahasa siswa kelas V SDN 1 Lenek Lauk berdistribusi normal.

Tabel 2. Hasil Uji Normalitas Data Kemampuan Berbahasa Siswa

\begin{tabular}{|ll|r|}
\hline & & \multicolumn{2}{|c|}{ Kemampuan Berbahasa } \\
\hline $\mathrm{N}$ & & 28 \\
Normal Parameters $^{\mathrm{a}, \mathrm{b}}$ & Mean & 73.9643 \\
& Std. Deviation & 6.73443 \\
Most Extreme & Absolute & .151 \\
Differences & Positive & .151 \\
& Negative & -.083 \\
Test Statistic & & .151 \\
Asymp. Sig. (2-tailed) & $.104^{\mathrm{c}}$ \\
\hline
\end{tabular}

Uji prasyarat berikutnya adalah uji linearitas data. Uji linearitas digunakan untuk mengetahui bentuk hubungan antara variabel bebas dengan variabel terikat, yaitu minat membaca dengan kemampuan berbahasa. Uji linearitas dihitung menggunakan bantuan 
SPSS 22 dengan ketentuan apabila taraf signifikansi lebih kecil dari 0,05 maka kedua variabel yakni minat membaca dan kemampuan berbahasa memiliki hubungan yang linear, begitu pula sebaliknya jika taraf signifikansi lebih besar dari 0,05 maka hubungan kedua variabel tidak linear. Berdasarkan hasil uji linearitas pada tabel output Anova diperoleh nilai signifikansi 0,009. Oleh karena sig. 0,009 < 0,05 dengan demikian dapat diambil kesimpulan bahwa variabel minat membaca dan kemampuan berbahasa siswa kelas V SDN 1 Lenek Lauk memiliki hubungan yang linear.

Tabel 3. Hasil Uji Linearitas Data

\begin{tabular}{|ll|r|r|r|r|l|}
\hline \multicolumn{1}{|l|}{ Model } & Sum of Squares & Df & Mean Square & F & Sig. \\
\hline 1 & Regression & 287.745 & 1 & 287.745 & 7.986 & $.009^{\mathrm{b}}$ \\
& Residual & 936.775 & 26 & 36.030 & & \\
Total & 1224.520 & 27 & & & \\
\hline
\end{tabular}

Data yang berdistribusi normal dan memiliki hubungan yang linier kemudian diuji hipotesis untuk mencari hubungan antara variabel minat membaca dan kemampuan berbahasa siswa kelas V SDN 1 Lenek Lauk. Pada penelitian ini untuk menguji hipotesis digunakan rumus Pearson Product Moment dengan bantuan program SPSS 22.

Langkah-langkah untuk mencari korelasi dengan bantuan SPSS 22 yaitu dengan cara input data kemudian klik Analyze > Correlate > Bivariate. Kemudian diperoleh nilai $\mathrm{r}_{\text {hitung }}$ sebesar 0,485 sedangkan nilai $r_{\text {tabel }}$ untuk N 28 adalah 0,375 pada taraf signifikansi 5\% $(0,485>0,375)$. Oleh karena itu dapat diperoleh kesimpulan bahwa terdapat hubungan yang signifikan dan positif antara minat membaca dengan kemampuan berbahasa siswa kelas V SDN 1 Lenek Lauk. Tingkat hubungan antara minat membaca dengan kemampuan berbahasa tersebut berada pada kategori sedang.

Tabel 4. Korelasi Minat Membaca dengan Kemampuan Berbahasa Siswa Kelas V SDN 1 Lenek Lauk

\begin{tabular}{|ll|r|r|}
\hline & & Minat Membaca & Kemampuan Berbahasa \\
\hline Minat Membaca & Pearson Correlation & 1 & $.485^{* *}$ \\
& Sig. (2-tailed) & & .009 \\
& $\mathrm{~N}$ & 28 & 28 \\
\hline Kemampuan & Pearson Correlation & $.485^{* *}$ & 1 \\
Berbahasa & Sig. (2-tailed) & .009 & 28 \\
& $\mathrm{~N}$ & 28 & \\
& & & \\
\hline
\end{tabular}

Proses analisis terakhir yang dilakukan adalah menghitung koefisien determinasi dengan tujuan mengetahui seberapa besar presentase sumbangan hubungan antara variabel minat membaca terhadap kemampuan berbahasa siswa kelas V SDN 1 Lenek Lauk. Berdasarkan analisis yang dilakukan diperoleh hasil perhitungan koefisien determinasi sebesar 23,5225\%. Hal ini berarti bahwa minat membaca memberikan kontribusi terhadap kemampuan berbahasa siswa kelas V SDN 1 Lenek Lauk sebesar 23,5225\% dan selebihnya 
dipengaruhi oleh faktor-faktor lain yang tidak diteliti dalam penelitian ini. Dengan demikian semakin tinggi minat membaca siswa, maka semakin tinggi pula kemampuan berbahasa yang diperoleh, begitu pula sebaliknya semakin rendah minat membaca maka semakin rendah pula kemampuan berbahasa yang diperoleh.

Hasil penelitian ini menunjukkan minat membaca siswa berada pada kategori sedang, yang berarti bahwa siswa kelas V SDN 1 Lenek Lauk memiliki kesenangan dan motivasi untuk membaca. Menjadikan kegiatan membaca tidak hanya sebagai bagian dari proses belajar mengajar tapi juga sebagai bagian dalam kehidupan sehari-hari. Begitu pula dengan hasil analisis kemampuan berbahasa siswa kelas V SDN 1 Lenek Lauk yang berada pada kategori sedang, sehingga hal ini menunjukan adanya hubungan positif diantara kedua variabel tersebut.

Hasil penelitian ini sejalan dengan teori mengenai membaca sebagai sarana menyerap kosakata serta pengetahuan bahasa. Selain itu membaca juga dapat meningkatkan daya cipta serta membantu mengekspresikan pemikiran baik melalui lisan maupun tulisan yang tentunya sangat membantu siswa dalam melakukan proses pembelajaran. Membaca menjadi salah satu kegiatan yang dapat meningkatkan kemampuan berbahasa siswa sehingga penting untuk meningkatkan minat membaca siswa. Untuk meningkatkan minat membaca, guru dan orangtua dapat mengambil peran masing-masing dalam memfasilitasi dan merangsang minat siswa. Hal tersebut sesuai dengan hasil penelitian yang dilakukan oleh Fauziah (2018), upaya guru dalam mengembangkan kemampuan membaca, menulis permulaan diantaranya yaitu dengan memberikan les tambahan, memberikan buku bacaan, memanfaatkan waktu belajar dengan baik, mendikte siswa, menggunakan metode membaca eja dan membaca lancar, memberikan motivasi, memberikan reward, memberikan bimbingan dan pengawasan, mengajak ke perpustakaan, dan memberikan penilaian.

\section{PENUTUP}

\section{Simpulan}

Hasil penelitian menunjukan adanya hubungan yang signifikan antara minat membaca dan kemampuan berbahasa siswa kelas V SDN 1 Lenek Lauk. Hal ini dibuktikan dengan data hasil korelasi pada tabel korelasi hubungan minat membaca dengan kemampuan berbahasa siswa kelas V SDN 1 Lenek Lauk dengan menggunakan bantuan SPSS 22 dengan hasil $r_{\text {hitung }} 0,485$ sebesar sedangkan $r_{\text {tabel }} 0,375$ sebesar pada taraf signifikansi $5 \%(0,485>0,375)$ serta menunjukan kategori korelasi berada ditingkat sedang. Koefisien determinasi menunjukan bahwa adanya hubungan antara minat membaca dengan kemampuan berbahasa siswa kelas V SDN 1 Lenek Lauk dengan kontribusi sebesar $23,5 \%$ dan sisanya ditentukan oleh faktor-faktor lain yang tidak diteliti dalam penelitian ini.

\section{Saran}

Berdasarkan penelitian yang dilakukan, maka saran yang dapat dikemukakan adalah sebagai berikut: Guru harus melatih kebiasaan membaca siswa sehingga dapat merangsang dan meningkatkan minat membaca siswa. Orangtua perlu memahami 
pentingnya membiasakan membaca bagi anak. Orangtua dapat membangun kecintaan anak terhadap buku sejak dini agar anak memiliki minat dalam membaca. Untuk peneliti selanjutnya yang akan melakukan penelitian yang sejenis, penelitian ini dapat menjadi referensi. Disarankan untuk lebih teliti dalam melakukan penelitian tersebut serta perlu adanya pengembangan indikator minat membaca.

\section{E. UCAPAN TERIMAKASIH}

Dalam penyusunan skripsi ini, penulis menyadari bahwa proses penyusunan skripsi ini tidak terlepas dari bantuan dan bimbingan berbagai pihak. Oleh karena itu, pada kesempatan ini dengan segala kerendahan hati penulis menyampaikan terimakasih dan penghargaan yang tulus kepada:

1. Dra. Hj. Siti Rohana Hariana Intiana, M.Pd. selaku dosen pembimbing I yang telah banyak memberikan bimbingan dalam menyusun skripsi ini.

2. Ida Ermiana, S.Pd., M.Pd. selaku dosen pembimbing I yang telah banyak memberikan bimbingan dalam menyusun skripsi ini.

3. Keluarga besar SDN 4 Lenek Lauk yang telah memberikan kesempatan peneliti untuk melakukan uji lapangan di SDN 4 Lenek Lauk.

4. Keluarga besar SDN 1 Lenek Lauk yang telah memberikan informasi dan pelayanan dalam penelitian skripsi ini.

5. Rizqi Fitriyana Surya yang telah menyelesaikan penelitian ini.

\section{DAFTAR PUSTAKA}

Fauziah, H. 2018. Upaya Guru dalam Mengembangkan Kemampuan Membaca Menulis Permulaan Siswa Kelas I MI. Elementary: Jurnal Ilmiah Pendidikan Dasar, 4(2), 173. doi:10.32332/elementary.v4i2.1241

Hartono. 2016. Manajemen Perpustakaan Sekolah. Yogyakarta: Ar-Ruzz Media.

Musaddat, S. 2017. Peningkatan Keterampilan Berbahasa Indonesia SD. Mataram: Arga Puji Press.

Rahayu, Dyah Kirana Agung. 2012. “Upaya Meningkatkan Keterampilan Berbicara Anak Melalui Penggunaan Media Cerita Bergambar pada Kelompok B2 TK Pertiwi 57 Bangunharjo Sewon Bantul”. http://eprints.uny.ac.id/id/eprint/7724. Diakses pada 27 Juni 2019 pukul 20:02.

Setyowati, Heny. 2016. "Pengaruh Minat Membaca terhadap Kemampuan Berbahasa Kelas V SDN Segugus II Gembongan". https://adoc.pub/pengaruh-minat-membaca-terhadapkemampuan-berbahasa-kelas-v-.html. Diakses pada 26 Juni 2019 pukul 10:47. 